\title{
Assessment of Nutritional Status and Macronutrients Adequacy of Traumatic Brain Injury Patients Attending Tertiary Health Care in Oman
}

\section{Ghazi Daradkeh ${ }^{1 *}$, Musthafa Mohamed Essa ${ }^{1,2}$, Ali AL - Maashani ${ }^{4}$, Samir Al-Adawi ${ }^{2,3}$, R Koshi ${ }^{2}$, Sameera Arabawi ${ }^{4}$, Rayan Amiri ${ }^{4}$ and Jokha Al Barashdi ${ }^{4}$}

${ }^{1}$ Department of Food Science and Nutrition, College of Agricultural and Marine Sciences, Sultan Qaboos University, Sultanate of Oman

${ }^{2}$ Ageing and Dementia Research Group, Sultan Qaboos University, Sultanate of Oman ${ }^{3}$ Department of Behavioural Medicine, College of Medicine and Health Sciences, Sultan Qaboos University, Sultanate of Oman

${ }^{4}$ Khoula Hospital, Ministry of Health, Sultanate of Oman

*Corresponding Author: Ghazi Daradkeh, Department of Food Science and Nutrition, College of Agricultural and Marine Sciences, Sultan Qaboos University, Sultanate of Oman.

DOI: $10.31080 /$ ASNH.2020.04.0625
Received: January 17, 2020

Published: January 28, 2020

(C) All rights are reserved by Ghazi

Daradkeh., et al.

\begin{abstract}
Objective: The aims of this study were to assess the nutritional status and nutritional adequacy of among attendees seeking consultation at the National Trauma Center, Oman, for the sequel of traumatic brain injury (TBI).

Method: Anthropometric measurements (weight, height, body mass index, skinfold thickness) were estimated using standard protocol. Dietary intake was assessed by using "24 - Hour recall method". Nutritional status and nutritional adequacy were analyzed electronically using a computer program (super tracker) to assess the adequacy/inadequacy of micronutrients.

Results: Approximately $46 \%$ of attendees were classified as having 'mild TBI' while $12.7 \%$ and $40.8 \%$ were classified as moderate and severe TBI respectively. In terms of nutritional parameters, half of the cohort was at high risk of malnutrition (50.7\%) while $12.7 \%$ and $36.6 \%$ were at moderate and no risk of malnutrition respectively. In terms of anthropometric status, $28.1 \%$ of attendees were underweight, while $16.9 \%$ and $7.1 \%$ were overweight and obese respectively. Approximately $30.2 \%, 43.0 \%, 24.8 \%$ and $54.1 \%$ were noted to have energy deficient in energy, carbohydrate, protein, and fiber respectively.

Conclusion: This study indicates that TBI patients in Oman are at a high risk of developing malnutrition, which in turn, could impede their road to recovery. Therefore, nutritional assessment and support is vital to improve patient's outcomes amongst the TBI population.

Keywords: Traumatic Brain Injury; Nutrition Adequacy; Nutrition Assessment; Malnutrition
\end{abstract}

\section{Introduction}

Traumatic Brain Injury (TBI) is a critical global public health burden affecting more than 10 million people worldwide. It has been estimated to surpass many diseases as the leading cause of morbidity and mortality by the year 2020 [1]. Approximately, 1.7 million cases have been diagnosed annually, with 52,000 deaths reported each year. The Center for Disease Control (CDC) also reported over 250,000 hospitalizations annually and over a million emergency department visits per year [2]. One third of all injury related deaths in the USA were related to TBI [3]. In addition to the sheer morbidity and mortality, TBI presents a major worldwide social, economic and health problems [4]. Epidemiological studies have been reported that TBI often occurs in all age groups but with a higher preponderance in young adults, and the rate for males is twice that of females [5]. Presently, over 3.2-5.3 million people live with disability and the resultant reduced quality of life due to TBI [6]. In countries of the Arabian Peninsula, TBI is a rapidly growing problem, closely paralleling the rapid economic development. The incidence of motor vehicle accidents and TBI has been progressively increasing in Gulf Cooperation Council (GCC) countries, and the figures are quite alarming, particularly in Oman [7].

Studies suggested that pathological responses following TBI are marked with a cascade of bodily reactivity characterized by hypovolemic shock, and decreased cardiac output, leading to cerebral edema, hematomas, hydrocephalus, intracranial hypertension, vasospasm, metabolic derangement, excitotoxicity, excitotoxicity, infection, and seizures [8]. There is also deranged neurochemical activity including an increase in the level of catecholamine, glucocorticoids, glucagon, increased release of pro-inflammatory 
cytokines (IL1, IL6, TNF- $\alpha$ ), and acute phase protein production [9] have also been reported in TBI. Such pathological changes are likely to impact on alimentary system.

Excessive protein breakdown as a result of hyper catabolism stimulated by pro inflammatory mediators and catecholamine are also common features of TBI. Protein catabolism appears to peak 8-14 days after injury and appears to be related to injury severity [10]. Therefore, discussion on the issues of nutritional status among TBI patients comes to the forefront. Inadequate nutrition support for TBI patients may result in malnutrition and muscle wasting [10]. This cachexia increases the duration of rehabilitation and length of hospitalization, increases difficulties in mobility, functional rehabilitation, and promoted the development and exacerbation of medical complications [11] as well as neurobehavioral impairments. To prevent the catabolic state and breakdown of muscle protein as a result of increased energy demands, accurate assessment and estimation of the caloric needs of TBI patients is a critical component in providing adequate nutritional support. With multiple injuries, hyper metabolism increases in a variable degree, and some studies [12-14] have reported that the mean resting rate increases by $117 \%-175 \%$ of the healthy resting rate. After 2-3 weeks of injury, 120-145\% of energy expenditure is required for TBI patients [15-20]. Furthermore, it was reported that adequate calories intake are essential for reducing squalea of TBI [21].

Delayed or persistent, drastic underfeeding of TBI patients could heighten the disability incurred. Nutritional status of TBI patients has been reported in some population around the globe and there is lack of reports in emerging economies like Oman. Alluded earlier, Oman has a high number of TBI. In order to fill the gap in the literature, we have conducted this cross-sectional study aimed to (i) evaluate the nutritional status and macronutrient adequacy and (ii) assess the effect of severity of the trauma on nutrient intake among patients with TBI attending only dedicated Trauma Center in Oman.

\section{Methods}

\section{Patients}

The Ethics Committee of our Institution approved this study and patients' written informed consent was obtained (MERC/11/03). This study was conducted in an outpatient neurosurgery clinic at Khoula Hospital (National Trauma Center) - Muscat - Oman from February 2014 to February 2015. Seventy seven TBI patients aged $18-65$ years, males and females. TBI is defined here as an injury to brain tissues caused by an external mechanical force as evidenced by a loss of consciousness, post-traumatic cognitive and behavioral changes or an objective neurological finding that can reasonably be attributed to the TBI on a physical or cognitive and behavioral status examination. Patients were invited to participate in an anonymous survey and interview to be detail below. This invitation was extended during routine outpatient visits or outpatient stay.

Informed consent was obtained. The exclusion criterion included pre-injury psychiatric or neurological history other than those resulting from a TBI. In addition, non - Omani patients and those who were known to have sensory or cognitive impairments that would preclude completion of the protracted assessment were excluded from the sample. The presence of cognitive impairment gauged using the Montreal Cognitive Assessment (MOCA) [22], it assesses different cognitive domains: attention and concentration, executive function, memory, language, visuoconstructional skills, conceptual thinking, calculations, and orientation. The present study include patient whose score on MOCA fall within 18-26. This is conventionally view as presentation of 'mild cognitive impairment [23]. Six subjects were excluded from the study due to incomplete 24- hour recall questionnaire (Figure 1).

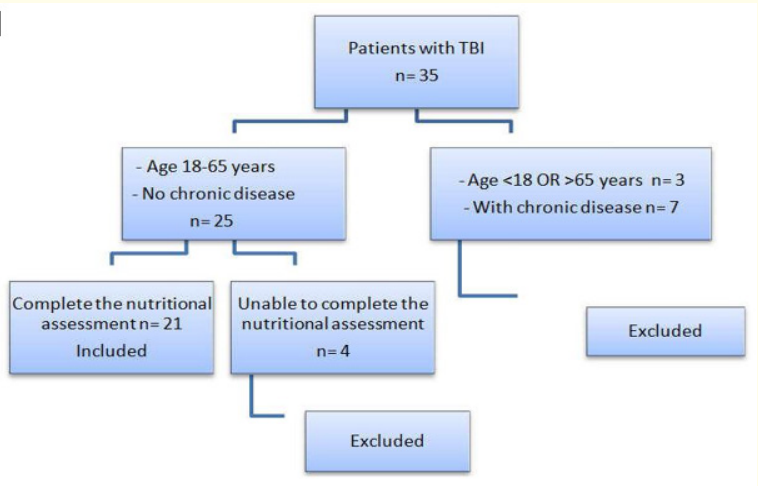

Figure 1: Flow Chart of Inclusion and Exclusion Procedure of Patients with Traumatic Brain Injury.

\section{Demographic characteristics}

Demographic information, including age, sex, education level, marital and smoking status were collected using a structured questionnaire. Weight was measured in kilogram to the nearest $0.1 \mathrm{~kg}$ using a digital weighing scale (Seca 208, Vogal and Halke, Germany) Height was measured to the nearest $0.5 \mathrm{~cm}$ by using a stadio meter protocol adapted from Lohman and colleagues [24] with a vertical measuring scale fixed to a metal bar connected to weighing scale. For patients who were unable to stand, height was estimated by using knee height equations as "stature $=85.10+1.73$ $\mathrm{x}$ knee height $-0.11 \mathrm{x}$ age" for men, "stature $=91.45+1.53 \mathrm{x}$ knee height $-0.16 \mathrm{x}$ age" for women [25], and by ulna length for males, height $(\mathrm{cm})=4.605 \mathrm{U}+1.308 \mathrm{~A}+28.003$, and for females, height $(\mathrm{cm})$ $=4.459 \mathrm{U}+1.315 \mathrm{~A}+31.485$ [26], and by demi-span for Males: height $(\mathrm{cm})=(1.40 \times$ demi span in $\mathrm{cm})+57.8$ and for Females: height $(\mathrm{cm})$ $=(1.35 \times$ demi-span in $\mathrm{cm})+60.0[27]$. 
The mean height of the three measurements was considered in calculations. Body Mass Index (BMI) was calculated as weight in kilograms divided by height in meters squared, i.e. BMI $=$ wt. $(\mathrm{Kg}) / \mathrm{ht}\left(\mathrm{m}^{2}\right)$ and the cutoff points of the World health organization were used [28]. Energy (Kcal), carbohydrate (gm), protein (gm), fat (gm) and fiber (gm) intakes were assessed by an expert dietitian by using the 24 - hour recall method [29] through faceto-face interview with each subject. Household utensils with different portions of common foods were used to assist the patients to report accurately and to check for an estimation of consumed foods. Food intake was analyzed electronically using electronic program (super tracker) [30]. The percentage of carbohydrate, protein, and fat was calculated as calories of each nutrient divided by the actual energy intake. Energy and protein adequacy on age and gender specific were calculated as the actual intake divided by Recommended Daily Allowances (RDA) [31].

\section{Nutritional status}

Nutritional status of all subjects was assessed by using "Malnutrition Universal Screening Tool” (MUST) [32] and classified as: no risk, moderate risk and high risk of malnutrition when MUST score was 0,1 and $\geq 2$ respectively.

\section{Level of disability}

Glasgow Coma Scale (GCS) was used to classify the severity of trauma, as mild when GCS $\geq 13$, moderate when GCS between 9-12 and severe when GCS $\leq 8$ [33].

\section{Statistical analysis}

Graph Pad Prism (version 6.0) was used for statistical analysis. Means and standard deviations (using t-tests for two means, one way ANOVA was used to compare between groups), two sided statistical significance was set at $\alpha \leq 0.05$ and Proportions were compared by using chi-square test.

\section{Results}

Patient demographics and clinical characteristics

From February 2014 to February 2015, 71 patients in the age group 18-65, with a mean age of 27.3 years that fulfilled the eligibility criteria were enrolled in the study. The majority of patients were males (61-85.9\%) and (10-14.1\%) were females, with 6.1:1 male to female ratio. Most of the patients $(75 \%)$ were aged between 18-30. 46.5percent of subjects were classified as mild TBI while $12.7 \%$ and $40.8 \%$ were classified as moderate and severe TBI respectively using Glasgow Coma Scale. Motor vehicle accidents were the most common cause of TBI (91.7\%), followed by falls from height $(8.3 \%)$.

\section{Nutritional and macronutrients status of TBI patients}

Half of the subjects were at high risk of malnutrition (50.7\%) while $12.7 \%$ and $36.6 \%$ were at moderate and no risk of malnutrition respectively. $28.1 \%$ of patients were underweight, while $16.9 \%$ and $7.1 \%$ were overweight and obese respectively.
The mean total energy intake (kilocalories) and macronutrients (as a percentage of totals energy) including protein, carbohydrate, and dietary fiber were compared with the recommended dietary allowances [29]. The proportion of the nutrient intakes below an acceptable range of RDA was used for inadequacy determination [48]. The participants mean intake was significantly lower in total energy by (30.2\%), carbohydrate by (43\%), protein by (24.8\%) and fiber by $(54.1 \%), p<0.000$. Figure 2 , compared with recommended dietary allowances [31,32].

The effect of trauma severity on nutrients intake among patients with TBI

The participants in the present study were deficient in fiber and macronutrient intakes. The mean intake of macronutrients and fiber were significantly lower than the recommended allowance (RDA) Figure 2. Our findings showed that the severity of trauma exhibited a negative impact on energy and protein intake $(\mathrm{p}<0.001$ and $<0.0001$ respectively) (Figure 3 and Figure 4).

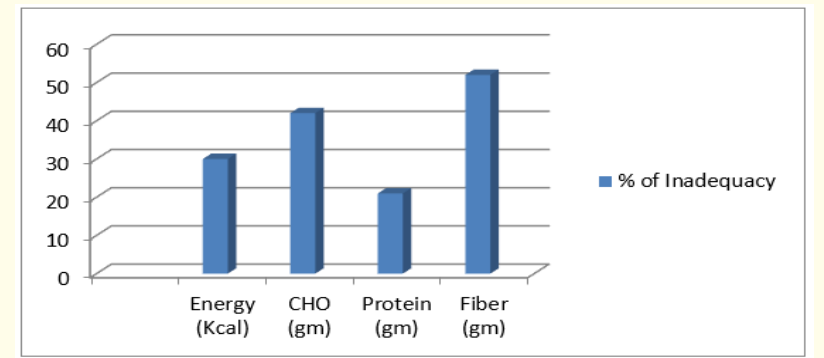

Figure 2: Percentage of Energy, Carbohydrate, Protein, and Fiber Inadequacy of TBI Participants Compared with Recommended Dietary Allowances.

Energy: $\mathrm{P}<0.000, \mathrm{CHO}, \mathrm{P}=0.03$, Protein: $\mathrm{P}=0.012$, Fiber $\mathrm{P}<0.001$.

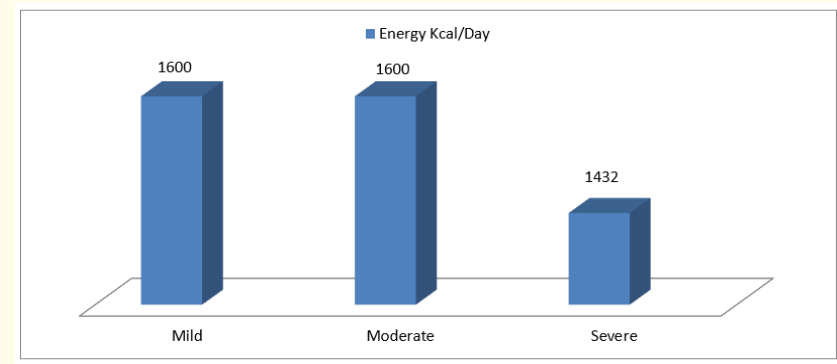

Figure 3: Energy Intake of TBI Patients with Severity of Trauma as Indexed by Glasgow Coma Scale.

\section{Discussion}

Epidemiological studies have been suggesting that globally, the most common cause of death and disability in young individuals under the age of 45 years is due to TBI [42]. 


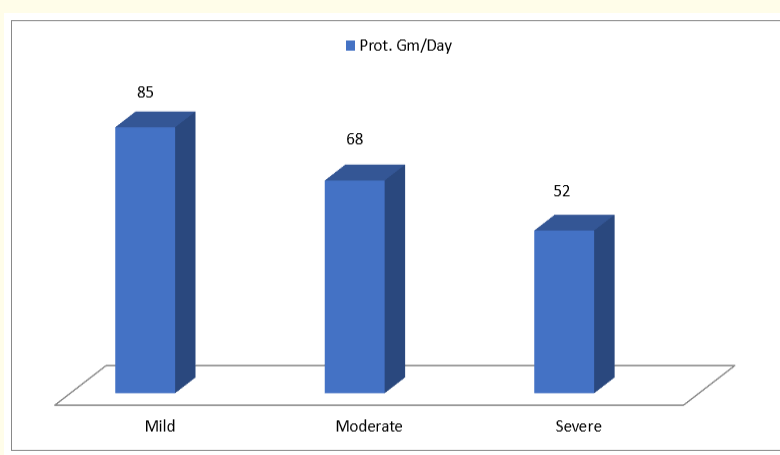

Figure 4: Protein Intakes of TBI Patients with Severity of Trauma as Indexed by Glasgow Coma Scale.

Triggered hyper- metabolism and catabolism have been associated with the pathobiology by TBI. Total energy expenditure, catabolism and gastrointestinal intolerances have been shown to be increased during the early post injury period in TBI patients [45] As well, dietary intake may be reduced, due to reductions in appetite sensation, and may be likely due to changes in the levels of cytokines, glucocorticoids, insulin and insulin-like growth factors. Pre surgery fasting, gastro paresis, and medication interactions may lead to dysphagia and gastrointestinal intolerance, impeding the ability to meet nutrition requirements in patients with TBI $[40,41,49]$.

Hyper metabolism, protein catabolism and altered gastrointestinal functions were reported to be common in TBI patients [34-36]. This is due to the increased release of catecholamine and cortisol [31,32], capable of releasing a cascade of neurochemical activities leading to increased nutritional demands [57]. This alteration in the demand for food intake could be one of the critical etiological factors that lead to development of malnutrition and its related complications [44].

Malnutrition is a common and dangerous health problem and it can be defined as inadequate and/or imbalanced nutritional intake, with adverse effects on physiological function and clinical outcome [43]. Moreover, protein-energy malnutrition (PEM) often occurs due to nutritional support insufficiency. The main signs of PEM are depletion of muscles, body fat and visceral protein stores. The trajectories of PEM has negative repercussion including rendering TBI patients with higher length of stay (LOS), increased morbidity and mortality rates along with social consequences [46] Bernstein., et al. 1995 [47] and Mears., et al. 1996 [48] reported that $30-50 \%$ of TBI patients suffer from PEM. Studies suggest that that prevalence of poor nutritional status in TBI patients is high. Therefore, this study has embarked to assess the nutritional status in TBI patients National Trauma Center in Oman.

Our results showed that $63.4 \%$ of TBI patients were at moderate to high risk of malnutrition, which corroborates with previous reports [35,38]. Deutsenman., et al. 1986 [35] and Hynes., et al.
1992 [38] reported that 58\% of TBI patients were below their ideal weight, and provides further evidence for the presence of malnutrition in these patients. Brooke., et al. 1989 [37], reported that $60.4 \%$ of TBI patients have a body weight of less than $90 \%$ of ideal weight [39]. Similarly, Krakau., et al. 2007 [40] found that $68 \%$ of TBI patients were malnourished within two months of TBI, according to the Malnutrition Universal Screening Tool (MUST) criteria. Another study showed that $76 \%$ of TBI patients showed progressive increase of malnutrition [41].

TBI patients were usually in a catabolic and hypermetabolic state. The severity and type of injury correlated to the degree of catabolic state, as categorized by Glasgow Coma Scale (GCS) score, which ranges from 15 (fully conscious) to 3 (near death) [19]. We found that $40.8 \%$ of the patients enrolled in our study were under severe TBI status, which is supported by Krakau., et al. 2007 [40]. They reported that $50 \%$ of the enrolled patients in their study were within the lowest range of GCS (3 to 5) which represents severe TBI. Another study also showed that there is a significant association with poorer admission, and the clinical features of malnutrition in TBI subjects [41].

Our results showed that protein intake was deficient $(24.8 \%)$ and varies as per severity of injury in TBI patients ( $p<0.0001)$. Protein intake of TBI subjects could be below the recommended daily intake, which is based on the severity of injury [53]. Dietary guidelines of energy intake for total and saturated fat recommends no more than $30 \%$ of calories from fat intake, and no greater than $7 \%$ of calories from saturated fat intake $[54,55]$. We found that the mean percentage of energy from total fat intake was within the recommended range (26.62\%) along with higher saturated fat intake (9.3\%). Tomey., et al. 2005 [54] reported that the mean percentage of energy from total fat and saturated fat was $36.2 \%$. Moussavi., et al. 2001. Reported that $36.7 \%$ of calories was derived from fat intake was in participants with spinal cord injury [56]. Both studies corroborate with our current findings.

Generally, the mean recommended dietary intake of fiber is 38 $\mathrm{g} / \mathrm{d}$ for men and $25 \mathrm{~g} / \mathrm{d}$ for women [54]. The mean fiber intake in our patient cohort was significantly below $(17.45 \mathrm{~g} / \mathrm{d})$ the adequate recommendations by 54.1\%. Walter., et al. 2009 [50] and Tomy., et al. 2005 [54] reported similar findings in their study population. These changes in food consumption were similar to changes to the general population in other developing countries [51,52]. Furthermore, they recommended to nutritional education sessions to improve fiber intake by focusing on high - fiber breakfast cereals and encouraging regular consumption of fruits and vegetables.

\section{Conclusion}

Traumatic brain injury patients enrolled in our study were malnourished and or at high risk of malnutrition. Herein, we have shown that the balance of macronutrients was shifted toward fat intake, while energy, protein and fiber intake were significantly 
deficient. Energy and protein intake correlated with the severity of trauma as predicted by The GCS. Nutrition assessment upon admission of TBI patients could be a vital factor in identifying patients with malnutrition, and prevention from nutrition-related Complications. The limitation of this study was that we did not have a direct measurement of some participants' height and weight; however, the accuracy of estimated height and Weight compared with real height and weight remains questionable in TBI patients [58].

\section{Bibliography}

1. Kraus JF., et al. "Incidence, severity and external Causes of pediatric brain injury". Amrican Journal of Diseases in Children 140 (1986): 687-693.

2. Faul M., et al. Traumatic brain injury in the United States: Emergency department visits, hospitalizations, and deaths, Centers for Disease Control and Prevention, National Center for Injury Prevention and Control, Atlanta, Ga, USA, 2010.

3. CDC. Quick Stats: injury and traumatic brain injury-related death rates by age-United States. Morbidity and Mortality Weekly Report 59.10 (2006): 303.

4. Maas AI., et al. "Moderate and severe traumatic brain injury in Adults". Lancet Neurology 7 (2008): 728-741.

5. Hannay HJ and Lezak MD. "The neuropsychological examination: interpretation". In Lezak D, HOwieson DB, Loring DW, editors, Neuropsychological assessment, $4^{\text {th }}$ edn. New York: Oxford University Press. Finfer SR, Cohen J. Severe traumatic brain injury. Resuscitation (2001): 48-77-90.

6. Zaloshnja E., et al. "Prevalence of long-term disability from traumatic brain injury in the civilian population of the United Statet 2005". Journal of Head Trauma Rehabilitation 23.6 (2008): 394-400.

7. Al-Reesi H., et al. "Economic growth, motorization, and road traffic injuries in the Sultanate of Oman, 1985-2009". Traffic Injury Prevention 14.3 (2013): 322-328.

8. Stocchetti N., et al. "Clinical application of intracranial pressure monitoring in traumatic brain injury: report of the Milan consensus conference". Acta Neurochirurgica 156.8 (2014): 1615-1622.

9. Young B., et al. "Nutrition and brain injury". Journal of Neurotrauma 8.1 (1992): S372-S383.

10. Denes Z. "The influence of severe malnutrition on rehabilitation in patients with Severe head injury". Disability and Rehabilitation 26 (2004): 1163-1165.

11. Brandi LS., et al. "Energy Expenditure and severity of injury and illness indices in multiple trauma patients". Critical Care Medicine 27 (1999): 2684-2689.
12. Faisy C., et al. "Assessment of resting energy Expenditure in mechanically ventilated patients". The American Journal of Clinical Nutrition 78 (2003): 241-249.

13. Plank LD and Hill GL. "Sequential metabolic changes following induction of systemic Inflammatory response in patients with severe sepsis or major blunt trauma". World Journal of Surgery 24 (2000): 630-638.

14. Clifton GL., et al. "Assessment of nutritional requirements of headinjured patients". Journal of Neurosurgery 64 (1986): 895 901.

15. Fried RC., et al. "Barbiturate therapy Reduces nitrogen excretion in acute head injury". The Journal of Trauma and Acute Care Surgery 29 (1989): 1558- 1564.

16. Young B., et al. "Metabolic and nutritional sequelae in the no steroid Treated head injury patient". Neurosurgery 17 (1985): 784-791.

17. Boullata J., et al. "Acurate determination of energy needs in hospitalized patients". Journal of the American Dietetic Association 107 (2007): 393-401.

18. Weekes E and Elia M. "Observations on the patterns of 24-hour energy expenditure Changes in body composition and gastric emptying in head-injured patients receiving Nasogastric tube feeding". Journal of Parenteral and Enteral Nutrition 20 (1996): 31-37.

19. Borzotta AP., et al. "Enteral versus parenteral Nutrition after severe closed head injury". The Journal of Trauma and Acute Care Surgery 37 (1994): 459-468.

20. Robertson CS., et al. "Oxygen utilization and Cardiovascular Function in head-injured patients". Neurosurgery 15 (1984): 307- 314 .

21. Hatton J and Ziegler TR. "Nutritional support of the neurosurgical patient". In: Tindall G, Cooper PR, Barrow DL, Eds. The Practice of Neurosurgery. Baltimore, MD: Williams and Wilkins (1998): 381-396.

22. Nasreddine ZS., et al. "The Montreal Cognitive Assessment (MoCA): a brief screening tool for mild cognitive impairment". Journal of the American Geriatrics Society 53.4 (2005): 695669.

23. Rahman TT and El Gaafary MM. "Montreal Cognitive Assessment Arabic version: Reliability and validity prevalence of mild cognitive impairment among elderly Attending geriatric clubs in Cairo". Geriatrics and Gerontology International 9.1 (2009): 54-61. 
24. Lohman T., et al. "Anthropometric standardization reference Manual". Champaign, IL: Human Kinetics Books (1988).

25. Cheng HS., et al. "Estimatig stature from knee height for adults in Taiwan". Chang Gung Medical Journal 24.9 (2001): 547.

26. Gauld LM., et al. "Hight prediction from ulna Length". Developmental Medicine and Child Neurology 46.7 (2004): 475-480.

27. Bassey EJ. "Demi-span as a measure of skeletal size". Annals of Human Biology 13 (1986): 499-502.

28. Organization WH. "World Health Organization". Global Database on Body Mass (2011).

29. Lim SL., et al. "Malnutrition and its impact on cost of hospitalization, length of stay, readmission and 3- years mortality". Clinical Nutrition 31.3 (2012): 345-350.

30. Ahuja JKA., et al. "USDA Food and Nutrient Database for Dietary Studies, 5.0. USDA", Agricultural Research Service, Food Surveys Research Group, Beltsville (2012).

31. Report of the Panel on Macronutrients, Subcommittees on Upper Reference Levels Of Nutrients and Interpretation and Uses of Dietary Reference Intakes, and the Standing Committee on the Scientific Evaluation of Dietary Reference Intakes. Dietary reference intakes for energy, carbohydrate, fiber, fat, fatty acids, cholesterol, Protein and amino acids (macronutrients). Washington, DC: National Academies Press (2005).

32. Henderson S., et al. "Do the malnutrition universal Screening tool (MUST) and Birmingham nutrition risk (BNR) score predict mortality in older hospitalized patients?". BMC Geriatrics 10 (2008): 26.

33. Kondrup J., et al. "ESPEN guidelines for Nutrition screening". Clinical Nutrition 22 (2003): 415-421.

34. Clifton GL., et al. "The metabolic response to severe Head injury". Journal of Neurosurgery 60 (1984): 687-696.

35. Deutschman CS., et al. "Physiological and metabolic Response to isolated closed head injury. Part 1: Basal metabolic state: Correlation of Metabolic and physiological parameters with fasting and stressed controls". Journal of Neurosurgery 64 (1986): 89-98.

36. Gadisseux P., et al. "Nutrition and neurosurgical patient". Journal of Neurosurgery 60 (1984): 219-32.

37. Brooke MM., et al. "Nutritional status during Rehabilitation after head injury". Journal of NeuroEngineering and Rehabilitation 3 (1989): 27-33.
38. Haynes MKM. "Nutrition in severely head-injured patient". Clinical Rehabilitation 6 (1992): 153-158.

39. Gadisseux P., et al. "Nutrition and neurosurgical patient". Journal of Neurosurgery 61 (1984): 76-86.

40. Krakau K., et al. "Nutritional treatment of patients with severe traumatic brain injury during the first six Months after injury". Nutrition 23 (2007): 308-317

41. Dhandapani SS., et al. "Clinical malnutrition in severe traumatic brain injury: Factors associated and outcome at 6 months". Indian Journal of Neurotrauma 4.1 (2007): 35-39.

42. Ghajar J. "Traumatic brain injury". Lancet 356 (2000): 923929.

43. Stratton RJ., et al. Disease-Related Malnutrition: Evidence Based Approach to Treatment, $1^{\text {st }}$ edn, Nutriticia Healthcare S.A, CABI Publishing, CAB International, Wallingford UK, (2003): 113-156.

44. Jackson AA. Severe malnutrition. In: Warrell DA, Cox TM, Firth JD, Benz EJ (eds). Oxford textbook of medicine, $4^{\text {th }}$ edn, vol 1. Oxford: Oxford University Press, (2003): 1054-1061.

45. McCall M., et al. "Effect of neuromuscular blockade on energy expenditure in patients with severe head injury". Journal of Parenteral and Enteral Nutrition 27 (2003): 27-35.

46. Bernstein LH. "Relationship on nutritional markers to length of hospital stay". Nutrition 11 (1995): 205S.

47. Bernstein L. "Measurement of Visceral Protein Status in Assessing Protein Energy Malnutrition: Standards of Care. Prealbumin in Nutritional Consensus Group". Nutrition 11.2 (1995): 169-171.

48. Mears E. "Outcome of Continuous Process Improvement of a Nutritional Care Program Incorporating Serum Prealbumin Measurements". Nutrition 12.7-8 (1996): 479-484.

49. Alhashemi HH. "Dysphagia in severe traumatic brain injury". Neurosciences 15.4 (2010): 231-236.

50. Walters JL., et al. "Evidence of dietary inadequacy in adults with chronic spinal cord injury". Spinal Cord 47 (2009): 318322.

51. Popkin BM., et al. "The nutrition transition and prevention of diet related diseases in Asia and the Pacific". Food and Nutrition Bulletin 22 (2001): 1-58.

52. Popkin BM. "An overview of the nutrition transition and its health implications: the Bellagio Meeting". Public Health Nutrition 5 (2002): 93-103. 
53. Sabour H., et al. "Calorie and Macronutrients intake in people with spinal cord injuries: An analysis by sex and Injury-related variables". Nutrition 28 (2012): 143-147

54. Tomey KM., et al. "Dietary intake and nutritional Status of urban community-dwelling men with paraplegia". Archives of Physical Medicine and Rehabilitation 86 (2005): 664-671.

55. Groah SL., et al. "Nutrient Intake and body habitus after spinal cord injury: an analysis by sex and level of injury". The Journal of Spinal Cord Medicine 32 (2009): 25-33.

56. Moussavi RM., et al. "Dietary and serum Lipids in individuals with spinal cord injury living in the community". Journal of Rehabilitation Research and Development 38 (2001): 225-233.

57. Blundell JE. "Pharmacological approaches to appetite suppression". Trends in Pharmacological Science 12 (1991b): 147-157.

58. Mrozek S., et al. "Brain Temperature: Physiology and Pathophysiology after Brain Injury". Anesthesiology Research and Practice (2012): 989487

\section{Assets from publication with us}

- Prompt Acknowledgement after receiving the article

- Thorough Double blinded peer review

- Rapid Publication

- Issue of Publication Certificate

- High visibility of your Published work

Website: https://www.actascientific.com/

Submit Article: https://www.actascientific.com/submission.php Email us: editor@actascientific.com

Contact us: +919182824667 